\title{
Issues in the Design of Facilitated Collaboration Processes
}

\author{
GWENDOLYN L. KOLFSCHOTEN
}

Faculty of Technology Policy and Management, Delft University of Technology, Jaffalaan 5, 2628BX Delft, The Netherlands

(E-mail: G.L.Kolfschoten@tbm.tudelft.nl)

\section{MARIËLLE DEN HENGST-BRUGGELING}

TNO Quality of Life, Business Unit Work and Employment, PO Box 718, 2130 AS Hoofddorp, The Netherlands

(E-mail: m.dhengst@arbeid.tno.nl)

\section{GERT-JAN DE VREEDE}

Institute for Collaboration Science, University of Nebraska at Omaha, 1110S. 67th Street, Omaha, NE, 68182-0116 USA

(E-mail: gdevreede@mail.unomaha.edu)

\begin{abstract}
Groups often rely on the expertise of facilitators to support them in their collaboration processes. The design and preparation of a collaboration process is an important facilitation task. Although there is a significant body of knowledge about the effects of facilitation, there is a dearth of knowledge about the ways in which facilitators design collaboration processes. Increased understanding in this area will contribute to the effective design and use of collaboration support and to the development of collaboration process design support. The research reported in this paper explores the strategies and techniques facilitators use to design a collaboration process, and the aspects of this task they perceive as challenging. We present the results of a questionnaire among professional facilitators. We compare facilitators with different expertise levels to identify challenges in the design of collaboration processes. We discovered that although the activities performed and information used by novices is not very different from expert practices, their limited experience makes them less flexible. When the actual session brings surprises such as different outcomes or conflict, novices cannot easily adapt their designs to accommodate these.
\end{abstract}

Key words: facilitation, facilitation techniques, collaboration process design, Collaboration Engineering, design and preparation, Group Support Systems

\section{Introduction}

Facilitation is an approach to collaboration support in which a variety of methods, tools and interventions are employed by facilitators to support groups in achieving their goals. Facilitators possess skills and knowledge that they employ to guide and motivate a group to achieve a specific outcome. One important step in facilitation is 
the design and preparation of an intervention. As described in the code of ethics of the International Association of Facilitators (IAF); "In dialogue with the group or its representatives we (facilitators) design processes that will achieve the group's goals, and select and adapt the most appropriate methods and tools" (International Association of Facilitators 2004).

Studies on Group Support Systems (GSS) implementation and use often highlight facilitation (Vreede et al. 2002), and in particular design of facilitated GSS interventions as the key success factor of GSS use (Nunamaker et al. 1997). Facilitators themselves indicate that preparation, i.e. meeting design, is their most important task (Clawson and Bostrom 1995). In general, facilitators feel that they perform this task relatively well and feel little need for support (Clawson and Bostrom 1995). However, field experiences suggest that poor preparation is a key cause for failure of GSS meetings. (Nunamaker et al. 1997; Vreede et al. 2003). Therefore, the design of group processes is of central importance to facilitation. Furthermore, knowledge and experience required to create effective designs is often tacit or described in manuals and handbooks such as (Dick 1991; Heron 1989, 1999; Hunter et al. 1992; Kamer et al. 1996; Rees, 1998; Schuman 2005; Schwarz 1994, 2002; Tropman 1996).

To understand the importance and practice of collaboration processes design by facilitators, we sampled perspectives on meeting design efforts from a large number of professional facilitators. The goal was to gain insights in the design process and the perceived key challenges in the preparation of a collaboration process. In addition, we wanted to find out if there are key differences between experts' and novices' approaches to design, to identify particular difficulties that novices face in collaboration process design but that experts have overcome. The findings of this research are not only of interest to corroborate the guidelines in manuals as indicated above, but also to confirm and extend our understanding of this challenging facilitation task. It is furthermore an important step to develop a design approach for Collaboration Engineering. Collaboration Engineering is a technology independent approach to deploy collaboration processes through the transition of a collaboration process design to practitioners in organizations (Vreede and Briggs 2005). In this approach the quality, predictability and transferability of the collaboration process design is of particular importance. Therefore we needed an integrated perspective of design practices from facilitators in a variety of disciplines to identify the design practices of facilitators and the challenges they encounter.

In summary we developed a questionnaire that was particularly aimed at:

- Verifying our understanding of the design efforts and challenges of facilitators,

- Gaining insight in the challenges that novice facilitators encounter when they design collaboration processes, but that are overcome by experts,

- Providing a basis for the development of tools and facilities that support facilitators in the design of collaboration processes, and

- Providing a basis for the development of training tools and programs for novice facilitators. 
The remainder of this paper is structured as follows: First we describe current approaches to the design of facilitated collaboration processes. Next we explain our research approach, followed by the results and a discussion. Finally, we present our conclusions and directions for further research.

\section{Background}

Research on facilitation is often found in combination with research on GSS. However, in practice facilitation is a much broader profession that employs a wide variety of tools and techniques from artistic ones to mathematical ones. As GSS represent but one of the aspects of preparation (Clawson et al. 1993), for our study we examined both GSS research and research on the design of collaboration processes in general.

Several frameworks, models, and guidelines exist that support a facilitator in the execution of a collaboration process. Examples include the guidelines from Schwarz (Schwarz, 1994), Butler (Butler and Rothstein 2004), and the Circle model of Baldwin (Baldwin 1994). By following these guidelines, the facilitator is expected to be able to create a pleasant, 'fair' collaboration process. Schwarz (Schwarz 1994), Forman (Forman and Selly 2001) and Yoong (Yoong 1995) also offer approaches for the preparation of a collaboration process. Their approaches resemble a standard problem solving process, similar to those described for creativity (Couger 1995), problem solving (Ackoff 1978; Mitroff et al. 1974), decision making (Simon 1973) and systems analysis and design (Checkland 1981). A conceptual aggregation of such problem solving processes is presented in (Vreede and Briggs 2005):

- Understand the problem

- Develop alternative solutions

- Evaluate alternatives

- Choose alternatives

- Make a plan

- Take action

- Monitor results

These steps give an overview of the design effort to be made by facilitators, but are still rather generic and provide little guidance for the critical choices in the design of a collaboration process.

Besides the steps taken to create a collaboration process design we are also interested in the information used in this process. To cover this information we can draw from the well-known input-process-output model used in GSS research (Nunamaker et al. 1991), see Figure 1. The input describes the setting in which the meeting is carried out. The process includes issues such as facilitation, process structure, process quality, and process gains and losses. The output describes taskrelated outcomes such as effectiveness and efficiency, and social outcomes such as satisfaction, consensus, commitment, and usability. 


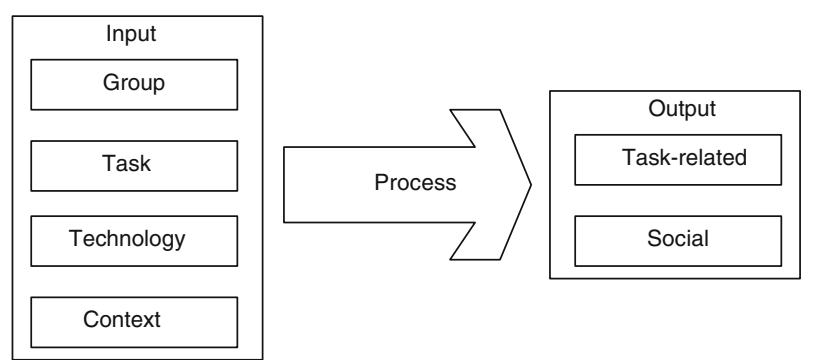

Figure 1. Input-process-output model.

For our research, we were mainly interested in the input-side of the model since this is most relevant during the preparation of a collaboration process. Four characteristics describe the input:

- Group characteristics including group size, group proximity, time, composition, and cohesiveness.

- Task characteristics including the activities to accomplish the task and task complexity.

- Technology characteristics can be described by components such as anonymity, group memory, speed, media characteristics, and user friendliness.

- Context characteristics including organizational culture, time pressure, evaluative tone, and reward structure.

Steps in the design process and aspects considered during the design should cover these input factors.

There are various studies that focus more explicitly on the choice of GSS tool in the context of meeting design. For example, Wheeler and Valacich (1996) and Dennis et al. (2001) describe how appropriate use of GSS can support effective collaboration processes. They suggest that this appropriate use should be supported through facilitation, training, restriction or guidance. Zigurs and Buckland (1998) describe a model that allows the user to identify a fit between task and GSS tool to support the selection and use of appropriate GSS tools. Antunes et al. (1999) presents a tool that supports the choice of a GSS tool based on strategies for different group tasks. By matching the group task to the different options in the system, the tool proposes appropriate GSS tools. These approaches all support the choice of group support tools and technology based on different criteria. Other frameworks for the design of a collaboration process are for instance the Divergence-Convergence model from Kamer et al. (Kamer et al. 1996), the Habermas model from Sheffield (Sheffield 2004), and various checklists such as provided by (Hunter et al. 1992; Rees 1998; Tropman 1996)

During preparation, various actors can be involved. For example, there can be a consulting team with (outside) experts, a steering team that usually consists of top 
managers that make decisions, a core team usually with middle managers and operational staff and a stakeholder team (Pourdehnad and Robinson 2001). The consulting team advices the facilitator on the collaboration process and are not related to the content of the collaboration process. The problem owners and decision makers of the collaboration process are part of the steering team and in many occasions they also participate during the collaboration process. The participants are part of the core team. The stakeholders are usually related to the content of the session but will not participate in the session. Finally, in technology supported facilitation, a technical assistant, called a technographer or a chauffeur (Dickson et al. 1996) is involved to select and prepare the most appropriate GSS tools for the process that the facilitator designs.

While each of these frameworks, \& approaches provides interesting guidelines, they often offer different perspectives that partly overlap but do not offer an inclusive overview of the practices and challenges of the design of collaboration processes. To integrate these perspectives we created overviews of the steps in design, the information used and the roles involved, based on the literature described above. We then wanted to gain insight in whether facilitators with different levels of experience indeed created their design as described and whether there are differences between different experience levels. These insights will guide the development of tools and facilities to support facilitators in the design of collaboration processes. Additionally, the differences or the lack of differences between novice and expert facilitators will give insight in approaches to support novice facilitators in their design efforts.

\section{Method}

To find out how facilitators design their collaboration processes we developed an exploratory questionnaire. ${ }^{1}$ The questionnaire consists of six parts, four of which are reported in this paper. Based on the findings described in Section 2 we built a list of steps in the design process and aspects that were taken into account in workshop design. Additionally we asked facilitators about their experiences and the people they involved in their design effort. Below we present a summary of the questions asked:

\subsection{Facilitation experience}

To distinguish novice facilitators from experienced ones, we inquired facilitators about their facilitation experience in terms of skillfulness, years of practice, and number of different facilitated workshops. In addition, we asked facilitators whether they prepared their workshops and the time they spend on preparation.

\subsection{Workshop design approach}

In this part we asked the facilitators about the design activities they execute during the preparation. We offered an extensive list of possible activities and additionally 
asked the facilitators to indicate other activities they performed in the design and preparation of a collaboration process.

\subsection{Information required for workshop design}

We addressed various aspects that facilitators take into account when designing a collaboration process concerning the group and task, and we asked whether the information regarding these aspects is generally available to them.

\subsection{Roles involved in preparation}

We asked the facilitators whom they involved in their design efforts. To identify the roles involved in the design process we used an open question. We coded the results to count the frequency of occurrence.

In addition to the questionnaire, an electronic discussion on designing workshops was analyzed. This discussion in particular addressed deviations between the plan/ design and the actual workshop and the purpose of design. The electronic discussion took place on an electronic list serve among facilitators. It was initiated by the authors and 15 facilitators responded.

Using the IAF's mail group and the website (International Association of Facilitators 2006) we solicited a response from approximately 200 facilitators who filled out the questionnaire. The respondents had a broad range of styles, methods, and work experience in many different environments, few used GSS; most facilitators used other tools and methods to support the group. We tried to build the questionnaire as generic as possible to accommodate all types of group facilitation. Despite this, it might have been difficult for some respondents to answer all questions. Some respondents explained their work situation, to provide the context for their answer. Questionnaires that contained multiple incomplete parts were excluded. As a result, 89 questionnaires were eventually taken into account.

\section{Results}

We used statistical tests (with SPSS) to reveal significant differences among novices, experienced and expert facilitators for the questions on design activities and information used. Differences among expertise were not significant or could not be analyzed, so the trends discussed below should be interpreted with caution and require further research in follow up interviews. Furthermore we did not take the relation between the domains facilitators operate in and the best practices used within that domain into account. Also, we did not investigate whether experienced facilitators use more complex combinations of GSS and other (manual) facilitation tools than novices and whether experts find tools more or less important. 


\subsection{Facilitation experience}

The questionnaire included various questions concerning the facilitator's experience. To determine the experience of the facilitator we looked at the number of workshops they had facilitated. We split the data set into facilitators who had facilitated less than 25 workshops (novices), between 25 and 100 workshops (experienced), and facilitators that had facilitated over a hundred workshops (experts), and compared their design efforts. From the 89 facilitators, 22 were categorized as novice, 28 as experienced and 39 as experts. In Table 1 their experiences are summarized. Expert facilitators who had conducted over a hundred workshops considered themselves more experienced, and had experience for more years. They have facilitated considerably more different groups within more different organizations. All facilitators, regardless of their experience prepared their workshops. The time facilitators take to prepare their workshop varied largely among and within expertise level. This is likely to depend more on the facilitation techniques used and the complexity of the task, than on the expertise level, as complex tasks might require for instance the configuration of computer tools or extensive interviewing prior to the collaboration effort, while simple tasks can be solved with off-the-shelve, readily prepared techniques. Generally, the time to prepare diminishes when experience increases, which is consistent with our expectation.

\subsection{Workshop design approach}

Table 2 summarizes the results regarding the execution of different activities in the design process. The table shows the percentage of the respondents who execute a particular design activity. The results show that novices often perform a task analysis, like their more experienced colleagues, but fewer novices perform an analysis of group and context. This is more often done by experienced and expert

Table 1. Summary of design experience and efforts.

\begin{tabular}{lllll}
\hline Question & & Novice $(n=22)$ & Experienced $(n=28)$ & Expert $(n=39)$ \\
\hline \# Sessions & Range & $1-25$ & $26-100$ & $101+$ \\
$\begin{array}{l}\text { Skill: } 1=\text { very unskilled, } \\
7=\text { very skilled }\end{array}$ & Mean (std) & $3.6(1.5)$ & $4.9(1.2)$ & $6.0(1.2)$ \\
\# Years experience & Mean (std) & $4.6(4.6)$ & $9.3(6.0)$ & $15.8(8.1)$ \\
\# Groups/clients & Mean range & $6-10$ & $26-50$ & $76-100$ \\
\# Organizations average & Mean range & $2-5$ & $11-25$ & $26-50$ \\
$\begin{array}{l}\text { Does prepare workshops } \\
\text { \# Hours preparation for a }\end{array}$ & Mean (std) & $100 \%$ & $100 \%$ & $100 \%$ \\
$\begin{array}{l}\text { 1/2 day workshop } \\
\text { \# Hours preparation for }\end{array}$ & Mean (std) & $15.6(24.4)$ & $11.6(7.0)$ & $6.3(7.5)$ \\
1 day workshop & & & & $11.3(13.4)$ \\
\hline
\end{tabular}


Table 2. Activities in a design process.

\begin{tabular}{lccc}
\hline Workshop design activity & Novice $(n=21)$ & Experienced $(n=28)$ & Experts $(n=39)$ \\
\hline 1 Analysis of task/problem & $90 \%$ & $96 \%$ & $90 \%$ \\
2 Analysis of group and context & $81 \%$ & $96 \%$ & $97 \%$ \\
3 Define tasks/steps & $90 \%$ & $86 \%$ & $87 \%$ \\
4 Define subtasks/steps & $57 \%$ & $57 \%$ & $59 \%$ \\
5 Explore possible techniques & $86 \%$ & $89 \%$ & $90 \%$ \\
6 Evaluate possible techniques & $48 \%$ & $61 \%$ & $72 \%$ \\
7 Choose techniques & $95 \%$ & $82 \%$ & $95 \%$ \\
8 Create a detailed hour by hour time frame & $86 \%$ & $68 \%$ & $79 \%$ \\
9 Create agenda & $95 \%$ & $100 \%$ & $100 \%$ \\
10 Document design & $57 \%$ & $75 \%$ & $82 \%$ \\
11 Try design on test group & $10 \%$ & $18 \%$ & $23 \%$ \\
12 Other aspects & $19 \%$ & $23 \%$ & $25 \%$ \\
\hline
\end{tabular}

facilitators. It is interesting to see that novices instead seem to pay attention more often to the definition of tasks and steps. Considerably fewer facilitators also consider subtasks.

The evaluation of possible facilitation techniques shows an increase with the expertise levels, which might indicate a learning curve. Also, the evaluation of different techniques is essential when facilitators have to consider and choose among a larger number of known techniques. In a separate question we asked how many different techniques a facilitator uses regularly. Novices used on average 6 techniques, experienced facilitators used on average 16 techniques and experts choose among 23 techniques. An hour by hour timeframe is created by many facilitators, but does not show any relation to experience. Almost all facilitators create an agenda. A large difference among design efforts is apparent in the documentation of the design. Whereas $82 \%$ of experts document their design, only $57 \%$ of novices do, which shows an interesting learning curve. Trying a design on a test group is not a common practice. Only a few facilitators mentioned other design efforts, including the preparation of (electronic) tools, visuals, decoration, multimedia etc, set up of the room, interviews or meetings/negotiation in advance, which mostly involved aspects of group and task analysis, the creation of very detailed manuals, and evaluation, validation and time estimation of the workshop. We asked about Tools used to support facilitators in preparation, some respondents mentioned MeetingWorks and GroupSystems, others mentioned books, models, checklists and manuals they used. 


\subsection{Information required for Workshop design}

The third part of the questionnaire addressed the importance of various aspects during the design phase and the availability of information that is pertinent to these aspects (see Table 3).

\subsection{Importance}

The importance of a goal for the workshop and the deliverables are considered high among all facilitators. Task complexity and task size are considered less important. The time-frame is considered important, consistent with the design activity "creating an hour by hour timeframe" (Table 2). It is interesting to note that in line with the pattern in Table 2, experienced facilitators perform this activity less frequently and consider the related information to be of less importance. The group size and the number of stakeholders are considered to be very important while other group aspects such as education level, organizational culture and institutionalized methods are considered less important.

Thus overall, we can conclude that group aspects are perceived to be less important than task aspects. This suggests that it may be possible to design collaboration processes and facilitation techniques that can be used for different types of groups, which is a common practice. The lower importance of group aspects is consistent with the analysis of the findings on novices, who address group aspects less frequently than task aspects (Table 2), but not with the analysis of the findings of experts, who often consider the group. This might be because experience shows that the impact of a group conflict on the success of a collaboration process is very large. However, since this is not a frequent problem, novices might be less aware of it, and therefore reluctant to take it into account during their design activities. It may also be that more experienced facilitators handle more complex collaboration processes where the role of the group aspects are more crucial.

\subsection{Availability}

In general all aspects score lower on the availability of relevant information than on importance except for the group size, timeframe, and task goal. If information on important aspects is not readily available, it becomes more difficult to interpret the situation and to create a suitable collaboration process. Although the differences are not significant many availability issues are scored lower by novices than by experts. Again several group aspects score lower than task aspects.

Finally, we asked facilitators what other information they needed that would help them in selecting among available facilitation techniques during the design of a workshop. The respondents indicated that they choose facilitation techniques based on predicted outcome of the technique, expected effectiveness and efficiency, logistics such as the room layout, participation or expected willingness to participate, client acceptance of the technique, and the facilitator's skill, preference, or experience. 


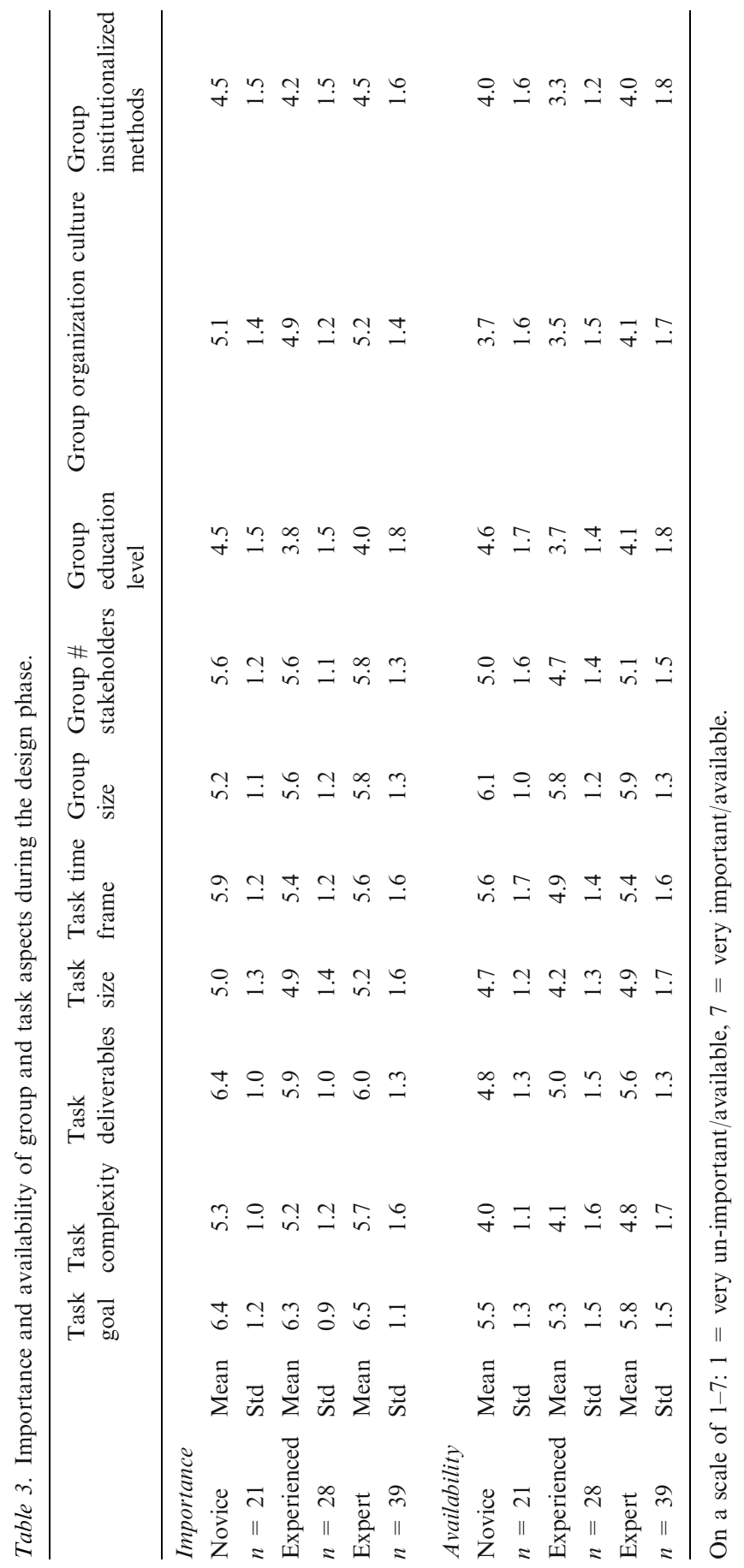




\subsection{Roles involved in preparation}

In Table 4 we present the percentage of facilitators that involved the listed roles in the design process, split out on experience levels.

Most facilitators involved the client or problem owner (steering team). Also many involve an assistant or colleague in the design (consulting team). Apparently, expert facilitators more often cooperate with other facilitators than novices and experienced facilitators. Only a small percentage (less than 20) involved participants and subject matter experts in the design phase (core team). It is interesting to note that experts involve stakeholders (note that we mean "content stakeholders" here: people with different stakes in the content of the outcome of the workshop) more often than novices and experienced facilitators (stakeholder team).

\subsection{Did it work out the way you planned?}

The final part of our study concerned an electronic discussion on workshop design and execution between 15 experienced facilitators. The discussion was fed with four questions:

- Do you think it is possible to plan and prepare a workshop so well that there are no surprises when you execute it?

- Is that worth the (extra) effort?

- What are the most occurring events/problems that make you change your plans during the workshop or meeting?

- What can you do to prevent these events from happening?

All facilitators agreed that it is impossible to plan and prepare a workshop in a way that there are no surprises when executed. Surprises will always occur. Dealing with surprises is part of the job of a facilitator. Examples of surprises mentioned by the facilitators are: malfunctioning technology and power failure, uncooperative stakeholders, new issues and new information that came up after the agenda was prepared, stakeholders disagreeing on the objectives and the importance or order of agenda items, different participants than planned, disorder in logistics (catering, room set-up) and strong power relations between participants. However, all these

Table 4. Roles involved in the design of collaboration processes.

\begin{tabular}{lccc}
\hline Roles & Novice $(n=21)$ & Experienced $(n=28)$ & Experts $(n=39)$ \\
\hline 1 Client/leader/problem owner/sponsor & $86 \%$ & $73 \%$ & $89 \%$ \\
2 Cofacilitator/assistants & $38 \%$ & $46 \%$ & $66 \%$ \\
3 Subject matter expert & $14 \%$ & $15 \%$ & $8 \%$ \\
4 Stakeholders & $14 \%$ & $12 \%$ & $29 \%$ \\
5 Few participants & $14 \%$ & $8 \%$ & $13 \%$ \\
6 All participants & $0 \%$ & $12 \%$ & $18 \%$ \\
\hline
\end{tabular}


issues do not imply that preparation is fruitless. All facilitators put great emphasis on preparation as a way to handle surprises. Preparation is necessary to become familiar with the goal, the topic, the material and the participants. This enhances the ability to sense where surprises might occur, to envision possible group dynamics and to prepare back-up plans for the least wanted surprises. Having a plan gives you ways to alter your plan. Facilitators need to be flexible when it comes to executing the plan (Hayne 1999; Niederman et al. 1996).

\section{Discussion and Conclusions}

The results underscore the importance of preparation and design. Almost all facilitators prepared their meetings, and many different design activities were executed. Furthermore, there is high consensus among facilitators that design is critical for the success of a session. Facilitators also stated that design is never a guarantee for success, but that it prepares them to deal with surprises and to adapt their workshop plan on the spot when such surprises occur. A good design seems to make a facilitator more flexible rather than inflexible. Our results support the literature that indicates that design is important for success of a collaboration process yet deviating from the design is custom rather than exception (Clawson et al. 1993; Nunamaker et al. 1997; Vreede et al. 2003).

When we compare novices with experts, generally their activities and the information they use is not that different. This might indicate that the difference between novices and expert facilitators is not in what they do, but how they do it. There is also another important difference between novices and experts. Novices do not know as many facilitation techniques as experts. This makes it less likely and harder for novices to achieve the optimal "fit" between task and facilitation techniques, and it will make them less flexible in adapting their design during the execution of the workshop when the chosen techniques appears to be a poor fit for the task or changes need to be made through task or group related surprises.

When we look at the facilitators' design approach, and compare it with a general problem solving process (until execution) as displayed in Table 5, we see the following. ,Understand the problem' has two distinct aspects for collaboration process design: the analysis of task and of group. These analyses can involve several interviews and negotiations with the client. Furthermore it requires a detailed decomposition of the process. To develop solutions, facilitators often use existing, familiar techniques that they apply to the situation at hand. ,Make a plan' for collaboration process design can be decomposed in a number of tasks like agenda building, making a time-frame, documentation, testing and performing a walk-through and preparing logistics, materials, manuals and tools.

When comparing the importance of information and its availability, we can draw a tentative conclusion. Both importance and availability were measured in sequence, in one part of the questionnaire and on the same scale. On all experience levels, facilitators scored availability lower than importance, except for the size and education level of the group. This overall difference in scores may indicate that in 
Table 5. Problem solving activities in collaboration process design.

\begin{tabular}{ll}
\hline Problem solving process & Activity for collaboration process design \\
\hline 1 Understand the problem & 1 Analysis of task/problem \\
& 2 Analysis of group and context \\
& 3 Define tasks/steps \\
& 4 Define subtasks/steps \\
2 Develop alternative solutions & 5 Explore possible techniques \\
3 Evaluate alternatives & 6 Evaluate possible techniques \\
4 Choose alternatives & 7 Choose techniques \\
5 Make a plan & 8 Create a detailed hour by hour time frame \\
& 9 Create agenda \\
& 10 Document design \\
& 11 Try design on test group \\
& 12 Other aspects \\
\hline
\end{tabular}

general, information that is important is not as readily available as facilitators would like it to be. From this perspective, "surprises" can be expected. It would be interesting to examine in detail the information that facilitators acquire or would like to acquire during the design of their workshops.

Literature shows us how to distinguish among different roles that facilitators consult during the preparation activities. It is interesting to see that the consulting team and steering team are frequently consulted during preparation, in contrast to the stakeholder team and core team that are hardly consulted. The stakeholder team and the core team have a lot of knowledge on the content of the collaboration process, whereas the consulting team and the steering team are more consulted to inform the design of the collaboration process. It appears that facilitators consider the content of the collaboration process to be of less importance during the preparation. Another interesting point is that novices have less access to a consulting team. This limits them to their own experience, and thus does not give them the ability to gain feedback on their design and possible problems that might occur.

In light of the above, we conclude that novice facilitators are more likely to encounter surprises, yet they are less equipped to handle these surprises. Therefore, design support for collaboration processes should contain more than a general' design approach. It should, for example, provide specific guidelines for design of and choice among facilitation techniques, and contain a library of proven facilitation techniques and best practices. Furthermore, such techniques should be documented in a way that makes them transferable and predictable (Kolfschoten et al. 2006; Vreede et al. 2005). This means that we should not only capture the process and instructions of a particular technique, but also, for example, insights on its applicability, possible alternative techniques, known pitfalls and guidance on how to overcome them. This will make the novice facilitator more flexible in preparing designs that are less sensitive to surprises and can be altered more easily when 
surprises force changes. These insights are also important in the light of Collaboration Engineering. When we want to transfer a collaboration process design to practitioners without facilitation experience, it is important to design collaboration processes such that their successful executing requires little improvising from the practitioner. In addition, the collaboration process design documentation has to assist practitioners in preparing for possible challenges and pitfalls.

The insights of this study give rise to a number of interesting directions for future research. First, we plan to further explore how we can assist novice facilitators, designers and practitioners by offering support in the choice among facilitation techniques. Second, further research is required on the documentation of facilitation techniques and designs to increase their transferability and predictability. We are planning to pursue these and other research avenues through a combination of focused questionnaires, semi-structured interviews, and small case studies.

\section{Acknowledgments}

We would like to thank Maureen and John Jenkins and Sandy Schuman for their support in spreading this questionnaire among the IAF and all respondents for their participation in this research. We gratefully acknowledge the constructive feedback from the anonymous reviewers and editors.

\section{Note}

1. The questionnaire can be requested from the first author, e-mail g.l.kolfschoten@tbm.tudelft.nl

\section{References}

Ackoff, R. L. (1978). The Art of Problem Solving. John Wiley \& Sons.

Antunes, P., T. Ho, and L. Carriço. (1999). "A GDSS Agenda Builder for Inexperienced Facilitators," In Proceedings of the 10th Euro GDSS Workshop. Copenhagen, Denmark: Delft University of Technology.

Baldwin, C. (1994). Calling the Circle: The First and Future Culture. New York: Bantam.

Butler, C. T. L. and A. Rothstein. (2004). On Conflict and Consensus; A Handbook on Formal Consensus Decision Making. Takoma Park: Food Not Bombs Publishing.

Checkland, P. B. (1981). Systems Thinking, Systems Practice. Chichester: John Wiley \& Sons.

Clawson, V. K., R. Bostrom, and R. Anson. (1993). "The Role of the Facilitator in Computer-Supported Meetings," Small Group Research 24, 547-565.

Clawson, V. K. and R. P. Bostrom. (1995). "The Importance of Facilitator Role Behaviors in Different Face to Face Group Support Systems Environments," In Proceedings of the Hawaii International Conference on System Sciences. Los Alamitos: IEEE Computer Society Press.

Couger, J. D. (1995). Creative Problem Solving And Opportunity Finding. Danvers, Mass: Boyd And Fraser.

Dennis, A. R., B. H. Wixom, and R. J. Vandenberg. (2001). "Understanding Fit and Appropriation Effects in Group Support Systems Via Meta-Analysis," Management Information Systems Quarterly 25, $167-183$.

Dick, R. (1991). Helping Groups to be Effective: Skills, Processes \& Concepts for Group Facilitation. Chapel Hill: Interchange. 
Dickson, G. W. et al. (1996). "Facilitating Computer Supported Meetings: A Cumulative Analysis In A Multiple Criteria Task Environment," Group Decision and Negotiation 5, 51-72.

Forman, E. H. and M. A. Selly. (2001). Decision by Objectives. World Scientific.

Hayne, S. C. (1999). "The Facilitator's Perspective on Meetings and Implications for Group Support Systems Design," DataBase 30, 72-91.

Heron, J. (1989). The Facilitators' Handbook. London: Kogan Page Ltd.

Heron, J. (1999). The Complete Facilitator's Handbook. London: Kogan Page Ltd.

Hunter, D., A. Bailey, and B. Taylor (1992). The Art of Facilitation: How to Create Group Synergy. Auckland: Tandem Press.

International Association of Facilitators (2004). Statement of Values and Code of Ethics for Facilitators. http://www.IAF-world.org.

International Association of Facilitators (2006). IAF Website. http://www.IAF-world.org.

Kamer, S. et al. (1996). Facilitator's Guide to Participatory Decision-making. Gabrolia Island: New Society Publishers.

Kolfschoten, G. L. et al. (2006). "Conceptual Foundation of the ThinkLet Concept for Collaboration Engineering," International Journal of Human Computer Science 64, 611-621.

Mitroff, I. I. et al. (1974). "On Managing Science In The Systems Age: Two Schemas For The Study Of Science As A Whole Systems Phenomenon," TIMS Interfaces 4, 46-58.

Niederman, F., C. M. Beise, and P. M. Beranek. (1996). "Issues and Concerns About ComputerSupported Meetings: The Facilitator's Perspective," Management Information Systems Quarterly 20, $1-22$.

Nunamaker, J. F. Jr. et al. (1991). "Electronic Meeting Systems to Support Group Work," Communications of the ACM 34, 40-61.

Nunamaker, J. F. Jr. et al. (1997). "Lessons from a Dozen Years of Group Support Systems Research: A Discussion of Lab and Field Findings," Journal of Management Information Systems 13, 163-207.

Pourdehnad, J. and P. J. Robinson. (2001). "Systems approach to knowledge development for creating new products and services," Systems Research and Behavioral Science 18, 29-40.

Rees, F. (1998). The Faciliator Exellence Handbook: Helping People Work Creatively and Productively Together. San Francisco: Jossey-Bass.

Schuman, S. (2005). IAF Handbook for Group Facilitation: Best practices from the Leading Organization in Facilitation. San Francisco: Jossey-Bass Publishers.

Schwarz, R. M. (1994). The Skilled Facilitator. San Francisco: Jossey-Bass Publishers.

Schwarz, R. M. (2002). The Skilled Facilitator. San Francisco: Jossey-Bass.

Sheffield, J. (2004). "The Design of GSS-Enabled Interventions: A Habermasian Perspective," Group Decision and Negotiation 13, 415-435.

Simon, H. A. (1973). "The Structure Of Ill Structured Problems," Artificial Intelligence 4, $181-201$.

Tropman, J. E. (1996). Making Meetings Work: Achieving High Quality Group Decisions. Thousand Oaks: Sage Publications.

de Vreede, G. J., J. Boonstra, and F. A. Niederman. (2002). "What is Effective GSS Facilitation? A Qualitative Inquiry into Participants' Perceptions," In Proceedings of the Hawaiian International Conference on System Science. Los Alamitos: IEEE Computer Society Press.

de Vreede, G. J. and R. O. Briggs. (2005). "Collaboration Engineering: Designing Repeatable Processes for High-Value Collaborative Tasks," In Proceedings of the Hawaii International Conference on System Science. Los Alamitos: IEEE Computer Society Press.

Vreede, G. J., R. O. de Briggs, and G. L. Kolfschoten. (2005). "ThinkLets: A Pattern Language for Facilitated and Practitioner-Guided Collaboration Processes," International Journal of Computer Applications in Technology 25, 140-154.

Vreede, G. J., R. de Davison, and R. O. Briggs. (2003). "How a Silver Bullet May Lose its Shine Learning from Failures with Group Support Systems," Communications of the ACM 46, 96-101.

Wheeler, B. C. and J. S. Valacich. (1996). "Facilitation, GSS and Training as Sources of Process Restictiveness and Guidance for Structured Group Decision Making an Emperical Assessment," Information Systems Research 7, 429-450.

Yoong, P. (1995). Assessing Competency in GSS Skills: A Pilot Study in the Certification of GSS Facilitators, SIGCPR.

Zigurs, I. and B. Buckland. (1998). "A Theory of Task/Technology Fit and Group Support Systems Effectiveness," Management Information Systems Quarterly 22, 313-334. 